\title{
Reflections on the Teaching of Packaging Design Based on Brand Strategy
}

\author{
Xuefang He \\ Academy of Fine Arts \\ Northeast Normal University \\ Changchun, CHINA \\ h567809@126.com
}

\author{
Bing Liu * \\ Academy of Fine Arts \\ Northeast Normal University \\ Changchun, CHINA \\ ice8515@163.com \\ Corresponding author
}

\author{
Shuzeng Li \\ Academy of Fine Arts \\ Northeast Normal University \\ Changchun, CHINA
}

\begin{abstract}
This paper analyzes the relationship between brand and packaging based on brand strategy, and analyzes the principles of packaging design adapted to the development of the market. In the process of packaging design teaching practice, the students are guided to establish brand awareness, on the basis of the brand strategy, the author puts forward the corresponding teaching strategies. It is of great significance to achieve the goal of packaging design teaching effectively through the cultivation of the students' brand awareness, the actual combat ability of packaging and packaging market.
\end{abstract}

Keywords_packaging design; brand strategy; brand image; teaching model

\section{THE RELATIONSHIP BETWEEN BRAND AND PACKAGING DESIGN}

\section{A. Packaging is the Material Carrier of Brand Image}

Packaging is the brand in the minds of consumers to establish materialized "tangible" image, is the consumer experience and brand awareness of the carrier, brand strategy has two tasks: one is to create a brand, the other is to maintain and enhance the brand, Packaging design is a kind of creative design activities, through the visual communication to the people of the implied and infected, thus subtly convey the brand information to consumers [1-3].

Modern packaging not only has the function of protection and storage of goods, and the material carrier of market competition, commodity circulation and cultural communication. Packaging in the use of the process, the company's direct purpose is to promote the brand, enhance consumer loyalty to the brand, packaging is not only the product of self introduction, but also product positioning, brand concept and value orientation of the comprehensive performance, is the most direct brand show. Consumers through the packaging of text layout, graphic design, color matching, etc. to understand the brand characteristics of the product, and to distinguish the visual language of packaging with other similar products. Brand image publicity to packaging design as the carrier; through the arrangement of the text layout, graphic design, color matching, and so on to understand the brand characteristics of the product, so that the brand presents a unique visual charm, and guide the consumer's consumption orientation and emotional connection $[4,5]$.

\section{B. Packaging is an Effective Means of Shaping the Brand}

Packaging as a business with the cultural symbols, through the visual elements to create a variety of consumer atmosphere, to achieve the brand's commercial value and use value. In the homogenization of the product today, a successful packaging to maximize the added value of the brand, so as to stimulate and induce consumers to buy desire. Packaging design not only the brand visualization, but also more simple to convey the brand information, its cultural content, emotional content is an effective means of shaping the brand, the brand packaging design platform to quickly put goods to market, to achieve the brand's commercial value [6].

Packaging design is the visual effects and psychological effects of unity, only in understanding the consumer's consumption habits and consumer psychology on the basis of the law to find changes in consumption in order to create a distinctive brand image. Packaging design from the visual to arouse the consumer brand association, will affecting the consumer's propensity to consume, according to DuPont's "DuPont Law", 63\% of consumers are based on the packaging and decoration of goods for purchase decisions. Packaging through the strengthening of consumer recognition and memory to shape the brand image, enhance consumer loyalty to the brand, good packaging to meet the needs of consumers and aesthetic needs, so that the design of the brand really have cultural value and commercial value. 


\section{A PRESS}

\section{PRINCIPLES OF PACKAgING Design UNDER BRAND STRATEGY}

\section{A. Business Principles}

In the era of market economy, the economic attribute of packaging determines that it must be a part of the whole market economy. The commercial principle of packaging is to use visual form, which can reflect distinctive character of product in the process of design, strengthen visual identity, accurately convey the product information, and achieve the purpose of product reservation and sale. Economic benefit is driving force for enterprise to develop product and improve design quality, packaging is designed to meet the material and spiritual needs of the people under premise, and efforts to achieve objectives and requirements of enterprise [7, 8].

As shown in Fig. 1 and Fig. 2, the packaging clever use of people's sense of association, the natural form simulation, abstraction and re creation, and enhance the visual appeal of packaging. Packaging in the visual communication design in line with the public's psychological and visual needs, to convey a clear message to consumers. Packaging in the design process, according to different nature of goods, form, circulation and other intentions, to determine positioning of commodity packaging, the only way to enhance the added value of packaging, and promote the sale of goods.

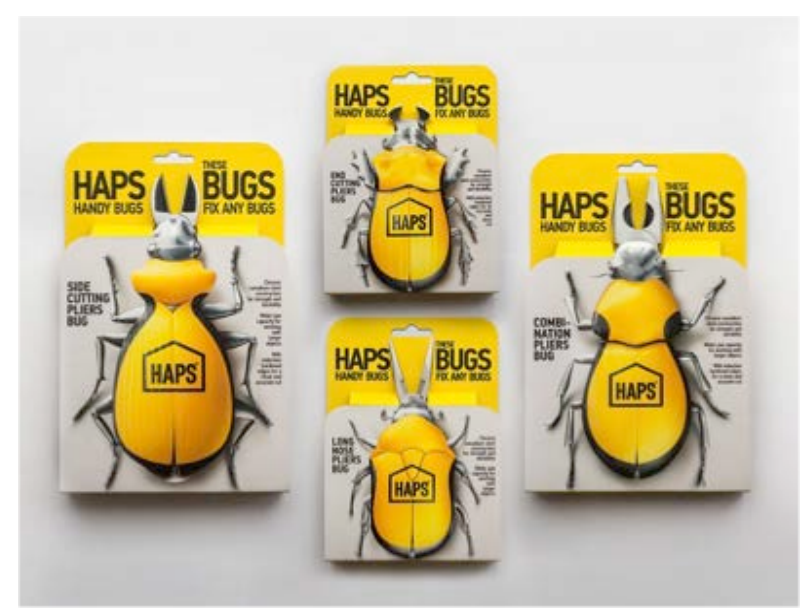

Fig.1. Example of packing design

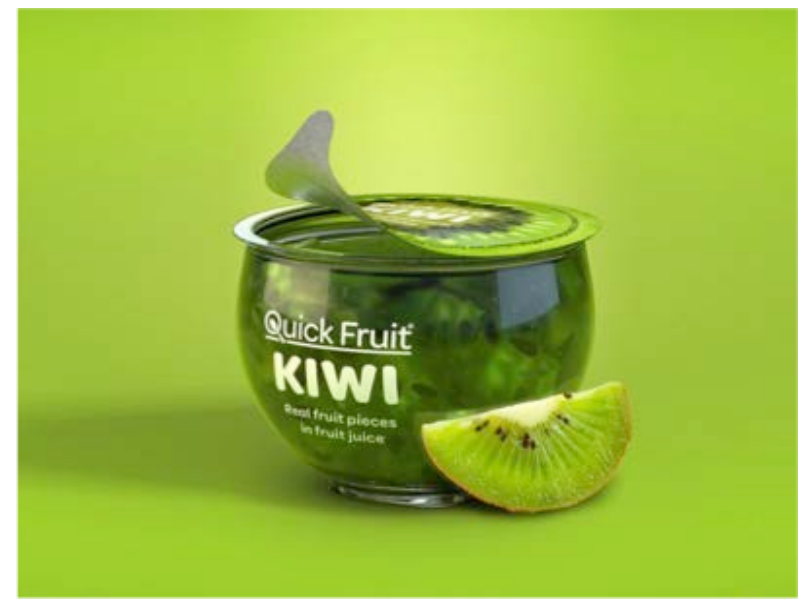

Fig.2. Example of packing design

\section{B. Artistic Principles}

Every level of society has its own way of life, language and behavior; the feeling of beauty is not the same. The artistic principle of packaging design refers to the inner and outer forms of packaging can arouse people's aesthetic experience, to meet people's pursuit of beauty; reflect aesthetic taste of times and society, so that people get material needs and functions at the same time, but also psychological pleasure. The art of packaging can mobilize people's own imagination and aesthetic ability, so as to obtain respect for others and meet themselves $[9,10]$.

The artistic principle of packaging design, on the basis of satisfying the material needs of people, tries to meet the spiritual life needs of people. As shown in Fig. 3 and Fig. 4, designed by the British design studio "Horse" farmer spring water packaging, using the animal fantasy scene, filled with rich colors, reflecting the mood of each season. This set of Changbai Mountain illustration packaging not only conveys the natural quality of the farmer spring, through the performance of the arts, won the goodwill of consumers, enhance the cultural tastes of enterprises, which are conducive to the cultural construction of enterprises, in the hearts of consumers to establish a good reputation, infection and enhance the aesthetic taste of the public.

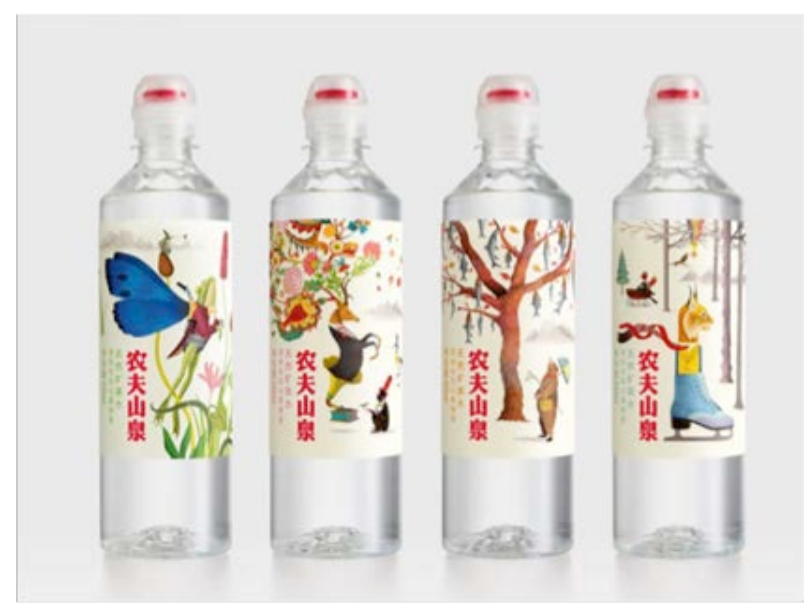

Fig.3. Example of packing design

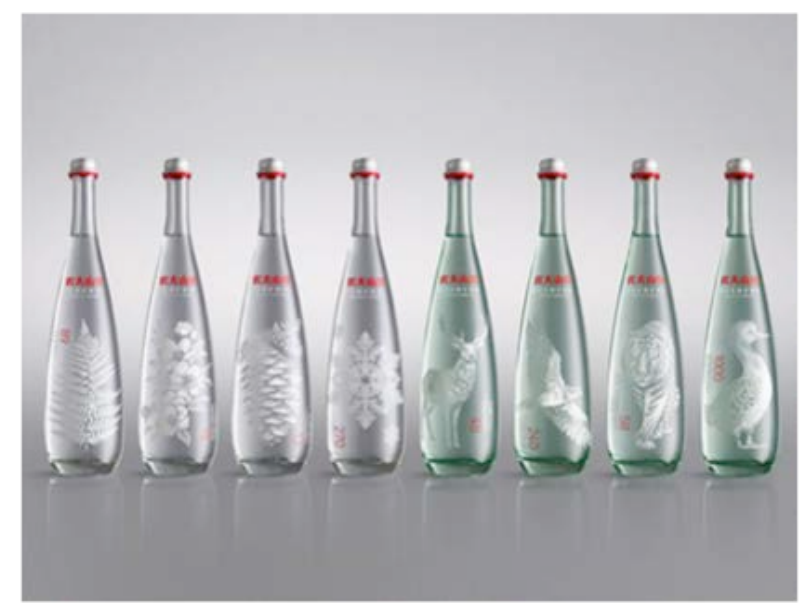

Fig.4. Example of packing design 


\section{Science and Technology Principles}

The essence of packaging design is the combination of art and technology. The scientific and technological principles of packaging design make the technology and use function closely together, make full use of modern scientific and technological means to improve the quality of products, the ultimate goal is to facilitate consumption, promote sales. The scientific principles conveyed in packaging design which is not only technology and skill in design, also includes the design concept of rationality and preciseness, which requires the choice of packaging materials and packaging structure set to meet visual orientation of consumer.

As shown in Fig. 5 and Fig. 6, the designer takes into account the fact that people are obstructed by the effect of air pressure when opening the product, this opening and closing of the bottle is ergonomically, so that opening method and structure are suitable for the physiological structure of the palm, easy to use and safe, this design has reliable sealing, suitable materials and sophisticated structure to better protect the product. Designers use their own knowledge and the design of the scientific theory, the scientific form of the law of beauty, to guide the design concept emotional design; the purpose is to highlight the image of goods, commodity information transmission.

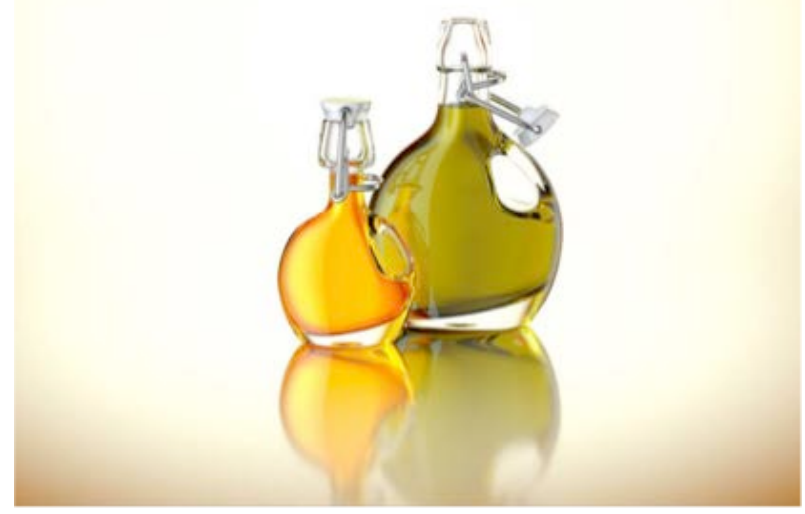

Fig.5. Example of packing design

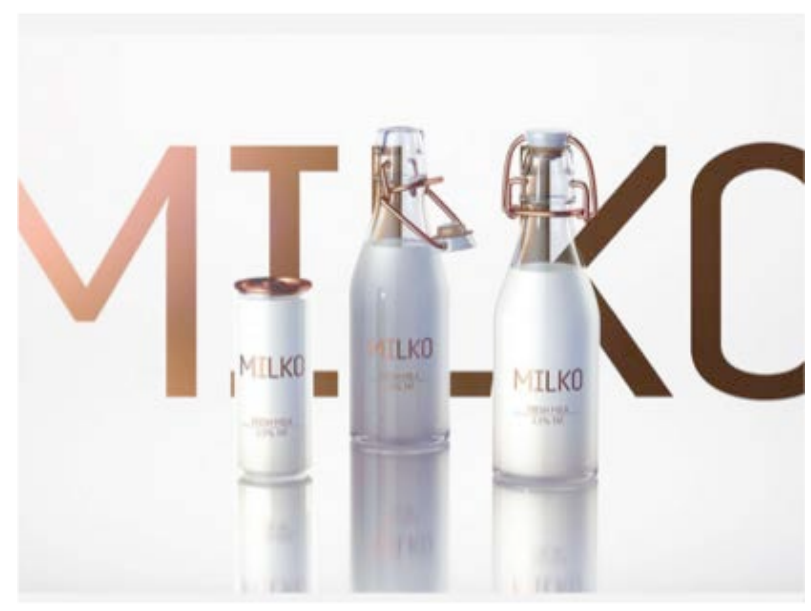

Fig.6. Example of packing design
III. TeAching Thinking OF PACKAgING Design Under BRAND STRATEGY

\section{A. To Enhance Students' Sensitivity to the Brand, to Improve the Brand Awareness of Student Packaging Design}

Packaging design to product-based, to shape and maintain the principle of brand, in the course of practical teaching, so that students fully understand the relationship between packaging and brand, pay attention to the sensitivity of the brand to strengthen the independent design training. Through the basic theory of guidance, the market for effective research, improve students' creative ability and practical ability, packaging design is the face of social and market work, only a comprehensive study of market information is possible to promote the completion of the design program.

In course of the curriculum, to explore the importance of packaging design on brand, concerned about the reality of market information, analysis of packaging behind the economic, cultural and environmental drivers, focus on cultivating students packaging design brand awareness, enhance student learning targeted and insight ability. Packaging design under the guidance of brand strategy, in the face of different brand demands, guide students to use the necessary theoretical knowledge, combined with the characteristics of the brand and modern means of production, to create conditions on explore the brand's appeal point, market-oriented into the brand creation, so that the new packaging design concept to attract customers on the basis of upgrading the brand image. As a kind of commercial packaging with cultural symbols, is one of the important role of the commodity into the market, is the physical carrier of brand core value, it created the brand image by visual elements, visual way to highlight the brand personality and brand commitment expression.

\section{B. To Establish Students to Market-oriented, Sales for the Purposes of the Strategic Packaging Design Awareness}

For the brand, the packaging design itself is a business behavior, the purpose is to obtain economic benefits, solve the problem of brand marketing, and promote the role of brand image, the only way to achieve economic benefits of packaging market, in economic activities, packaging is an effective way to increase the value of brand capital, is to guide consumption, the formation of an important factor in fashion. In the process of teaching, teachers as the organizers of learning, to guide students to dare to break through previous design concepts, grasp latest design dynamics, fully understand characteristics of the brand, quality, in-depth study of consumption, find out the consumption structure, development of consumption and the law of change. Research and analysis of social consumption at all levels of psychology, with the market test packaging design, design ideas closely around the market services, so that the concept of the brand to meet consumer psychology, attract customers, and ultimately achieve the purpose of consumption.

Packaging design is not only landscaping products, it is more directly involved in a market competition in the sales strategy, packaging design is to create the brand value of the necessary means, packaging design is to create the brand value 
of the necessary means, through the products or services provided to achieve the purpose of profitability. Enterprises through packaging design to promote the promotion of goods, the implementation of brand strategy, increase profits, expand reproduction, packaging business function is the most direct marketing of goods purposes, is the brand and consumer communication between media.

\section{The Establishment of Multi-functional Packaging Design Courses to Enhance the Market Competitiveness of Strategic Packaging Design}

With the development of times, the brand strategy-teaching model replaces simple creative teaching mode in the past, the diversified packaging teaching should meet the ability of the developed and cutting-edge packaging market to grasp and operate, guide consumers to consume, appreciate and change the use way and lifestyle; through the guidance of basic theory, the school will innovate content of the course and method of course, so as to improve design ability of the students. The purpose of packaging design is meet the basic requirements of social consumption, solved the problem of waste on resources and excessive packaging, be able to recycle and reuse, in other areas of life can also play its role.

Packaging design has obvious characteristics of the times, the packaging design of each era is a visual reflection of the economic, technological, cultural and social life of an era, the artistic expression of packaging design not only makes people look back on the concept of consumption, but also preserves and develops the values of people. When we are engaged in packaging design activities or creative works, we should appreciate the excellent diversified packaging design works, analysis its performance techniques and visual elements of the combination of forms, so that students in-depth and thorough understanding its thinking and dissemination of the effect; in the process of design, according to the product, consumer and the development of the market changes, constantly changes improve their own design thinking and expression, so as to design more in line with the enterprise, to meet the consumer, functional diversified commodity packaging.

\section{CONCLUSION}

Higher art design education should aim at cultivating innovative art design talents, in the teaching reform and research of packaging design, based on the combination of theory and practice, the combination of depth and breadth, and the combination of art and technology; through the integration and optimization of curriculum structure, update and adjust the teaching content, explore and innovate teaching methods, to improve the brand awareness of the students, so that students learn how to accurately convey the brand information, the combination of multiple packaging design courses and brand strategy, to achieve the comprehensive training of students' design ability. Packaging design teaching only for the market, according to the law of development of the market, continuous innovation, in order to train more qualified personnel in line with market demand.

\section{CORRESPONDING AUTHOR}

Bing Liu, Associate professor, Academy of Fine Arts, Northeast Normal University, China, ice8515@163.com.

\section{REFERENCES}

[1] Zhi fu, Yirong Su, Shaochao Dong, “Package Design”, Tsinghua university press, 2017. (in Chinese)

[2] Ruth Mugge, Thomas Massink, Erik Jan Hultink, "Designing a Premium Package: Some Guidelines for Designers and Marketers", An International Journal for All Aspects of Design, vol.17 (4), pp.583-605, 2014.

[3] Jan Schoormans, Marloes Eenhuizen-van den Berge, Gaston van de Laar, Lianne van den Berg-Weitzel, "Designing Packages that Communicate Product Attributes and Brand Values: An Exploratory Method”, The Design Journal, vol.13 (1), pp.31-47, 2010.

[4] Yanki Lee, "Design participation tactics: the challenges and new roles for designers in the co-design process”, CoDesign, vol.4(1), pp.31-50, 2008.

[5] Li li, “Package Design”, Machinery Industry Publishing House, 2016. (in Chinese)

[6] David Aaker, Ning-zi Wang, "Master of the brand: 20 rules to create a successful brand”, CITIC Publishing House, 2015, pp. 118-134

[7] Allison Ford, Crawford Moodie, Gerard Hastings, "The role of packaging for consumer products: Understanding the move towards 'plain' tobacco packaging”, Addiction Research \& Theory, vol.20 (4), pp.339-347, 2012.

[8] Tong He, "Packaging Creative Design", Southwestern Normal University press, 2013, pp. 107-117. (in Chinese)

[9] Natalia Vila, Olga Ampuero, "The Role of Packaging in Positioning an Orange Juice”, Journal of Food Products Marketing, vol.13 (3), pp.21-48, 2007.

[10] Xiaogang Liu, Xiaojie Cao, Jun Li, "Brand value theory”, Donghua University press, 2010. (in Chinese) 